\title{
Modulation of host cell signaling pathways as a therapeutic approach in periodontal disease
}

\author{
João Antonio Chaves de SOUZA 1 , Carlos ROSSA JUNIOR², Gustavo Pompermaier GARLET ${ }^{3}$, Andressa Vilas Boas \\ NOGUEIRA ${ }^{1}$, Joni Augusto CIRELLI ${ }^{2}$
}

1- DDS, MSc, PhD student, Department of Diagnosis and Surgery, School of Dentistry, UNESP-Univ. Estadual Paulista, Araraquara, SP, Brazil.
2- DDS, MSc, PhD, Professor, Department of Diagnosis and Surgery, School of Dentistry, UNESP-Univ. Estadual Paulista, Araraquara, SP, Brazil.
3- DDS, MSc, PhD, Professor, Department of Biological Sciences, Bauru School of Dentistry, University of São Paulo, Bauru, SP, Brazil.

Corresponding address: Joni Augusto Cirelli - Rua Humaitá, 1680 - Centro - 14801-903 - Araraquara, SP - Brazil - Phone: +55-16-3301-6375 - e-mail: cirelli@foar.unesp.br

Received: May 13, 2010 - Modification: June 21, 2010 - Accepted: October 26, 2010

\section{ABSTRACT}

\begin{abstract}
$\mathbf{R}$ ecently, new treatment approaches have been developed to target the host component of periodontal disease. This review aims at providing updated information on hostmodulating therapies, focusing on treatment strategies for inhibiting signal transduction pathways involved in inflammation. Pharmacological inhibitors of MAPK, NFKB and JAK/ STAT pathways are being developed to manage rheumatoid arthritis, periodontal disease and other inflammatory diseases. Through these agents, inflammatory mediators can be inhibited at cell signaling level, interfering on transcription factors activation and inflammatory gene expression. Although these drugs offer great potential to modulate host response, their main limitations are lack of specificity and developments of side effects. After overcoming these limitations, adjunctive host modulating drugs will provide new therapeutic strategies for periodontal treatment.
\end{abstract}

Key words: Periodontitis. Signal transduction. Janus kinases. STAT transcription factors. Mitogen-activated protein kinases. NF-kappa B.

\section{1- ETIOLOGY AND PATHOGENESIS OF PERIODONTAL DISEASES}

The hallmark of inflammatory/infectious conditions is the increased production of cytokines, proteases and other pro-inflammatory mediators. The synthesis and expression of these mediators occur in a transitory and strictly controlled way, seeking resolution of the problem and reestablishment of the homeostasis. Regulation of cytokine gene expression is controlled by various mechanisms, including transcriptional, post-transcriptional, translational and posttranslational regulations. In the event of defective negative regulation of cytokine gene expression, the exaggerated and uncontrolled expression of cytokines and proteases can have deleterious consequences to the host, including cancer, autoimmune and chronic diseases ${ }^{2}$. Periodontal disease is one of these chronic pathologies, and it is probably the most significant cause of tooth loss in adults ${ }^{10}$. The pathologic mechanisms of periodontal disease are still not completely understood. Current knowledge concerning the pathogenesis of periodontitis suggests that it is a mixed infection in which the host response to bacterial biofilms is associated with high levels of pro-inflammatory mediators. These mediators trigger a cascade of events that, in some individuals, culminate in the irreversible degradation of connective and bone tissues, and consequent periodontal attachment loss 6,57 . Periodontal diseases have unique characteristics that distinguish it from other common infectious diseases: there is no uniformity on the bacterial profile associated with disease; and there is no definite minimum level of infection that would result in disease in all individuals. Certain individuals seem to be more susceptible to periodontal disease and the variability in the host response seems to be a major cause of the disease extension and severity. Environmental and acquired risk factors as diabetes mellitus, psychological stress, smoking, and genetic factors [such as interleukin-1 (IL-1) gene polymorphisms] 
can accentuate the host inflammatory response and, consequently, the susceptibility to periodontal disease ${ }^{1,40}$. The association of periodontal disease with increased levels of cytokines and proinflammatory mediators suggests that endogenous mechanisms for the negative regulation of these genes may be defective or dysfunctional; and this, in turn, may be one mechanism of increased susceptibility to periodontal disease.

Many studies have shown that the biological activity of a variety of cytokines may be directly relevant to periodontal destruction ${ }^{2,29}$. The interaction between cytokines and their antagonists will ultimately determine the severity and extent of tissue destruction, which may occur either as a direct effect of increased level of cytokines, or as indirect consequences of cytokine expression ${ }^{57}$. There is evidence of changes in the expression of these immune regulatory molecules found in diseased sites, compared to health clinic conditions. While inflammatory mediators [IL-1, IL-6, and tumor necrosis factor-a (TNF-a)] and the T helper 1 cytokine interferon- $y$ (IFN- $\mathrm{Y}$ ) have been associated with higher periodontal disease severity, the opposite is considered true for $\mathrm{T}$ helper 2 type cytokines, such as IL-4 and IL-108,19,21. The balance between the expression of $\mathrm{T}$ helper 1 and $\mathrm{T}$ helper 2 type mediators is thought to be a relevant factor in the outcome of disease, possibly regulating the balance of anti-/pro-inflammatory cytokines, matrix metalloproteinases (MMPs)/tissue inhibitors of metalloproteinases (TIMPs) and receptor activator of nuclear factor- $\mathrm{KB}$ ligand (RANKL)/osteoprogerin (OPG). Imbalances between these mediators in the periodontal tissues are a major cause of periodontal destruction $22-23,46$.

\section{2- TRADITIONAL THERAPY AND NEW THERAPEUTIC STRATEGIES ON PERIODONTAL DISEASES}

The therapeutic approach to managing periodontal diseases has been traditionally targeted to the reduction and/or modification of bacteria in the dental biofilm. Albeit effective, this approach encumbers significant effort and requires periodic maintenance 82 . More recently, modulation of the host component of periodontal disease has been studied as an alternative therapeutic approach. Manipulation of the immune response to suppress undesirable reactions is an established therapeutic approach not only to various inflammatory and autoimmune diseases but also in cancer ${ }^{25,38}$. The purpose of host modulatory therapy is to restore balance between pro-inflammatory mediators and anti-inflammatory mediators. Recent studies have demonstrated that modulation of the host immune/ inflammatory response resulted in significant adjunctive benefits to scaling and root planning in the treatment of chronic periodontitis ${ }^{71}$. The adjunctive use of host modulatory therapy can slow down the progression of the disease, especially in susceptible patients at increased risk for whom conventional therapeutic approaches are not effective. Importantly, modulation of host response can prevent and/or minimize the destruction associated with the inflammatory process.

There are several strategies for modulation of host response. Studies suggest that certain local and systemic pharmacologic agents, that block specific inflammatory mediators, appear to attenuate disease progression ${ }^{90}$. Modulating biochemical agents and drugs have been postulated to be of therapeutic value as an adjunctive therapy to the management of chronic periodontitis ${ }^{28,42,65}$. The most studied drugs are antibiotics used in non-antimicrobial doses (e.g. tetracycline derivatives, which inhibit collagenolytic activities and activity of neutrophils and osteoclasts), antiinflammatory agents and bone-sparing drugs. The anti-inflammatory agents are mainly nonsteroidal anti-inflammatory drugs (NSAIDs) and weak organic acids, which prevent prostanoid formation by blocking the cyclooxygenase pathway of arachidonic acid metabolism. The bonesparing drugs (e.g., bisphosphonates) bind to the hydroxyapatite crystals of bone and prevent their dissolution by interfering with osteoclasts activity, thus reducing alveolar bone loss.

Inhibition of inflammatory mediators as nitric oxide (NO), IL-6, IL-1, TNF-a, MMPs and other proteases and pro-inflammatory cytokines have demonstrated successful protective effects against bone resorption ${ }^{18,44,54}$. The use of anti-cytokine therapies (by anti-cytokine drugs and soluble cytokine blockers) has been proven effective to block the negative effects of cytokines, slowing down the disease process. However, most of these drugs are associated with significant unwanted side effects, including hemorrhage, gastrointestinal problems, and renal and hepatic impairment that preclude their use. Another important consideration is the protective role of immune response and the potential hazards of its negative modulation, especially aggravation of infection as demonstrated by studies using animals with defective immune response and clinical studies in severely immunocompromised patients ${ }^{11,16-17}$.

A more recent approach to modulation of the levels of inflammatory mediators involved in the immune response is targeting cell signaling pathways important for their gene expression. One advantage of this approach is that expression of various inflammatory mediators requires activation of a limited number of these signaling pathways. Thus, modulation of one signaling 
pathway may affect expression of more than one inflammatory mediator and alter the whole cytokine network. This is important considering the frequently redundant and interchangeable role of inflammatory mediators and cytokines and also implies that the impact of therapies targeting a single cytokine or inflammatory mediator may be somewhat limited because of compensatory mechanisms ${ }^{30}$. As promising and attractive as these strategies may be, intracellular signaling pathways have some important characteristics that should be considered, including the fact that they may be essential to various cellular processes, such as proliferation, apoptosis and survival. This suggests that modulation of some cell signaling pathways may have negative effects; however another hallmark of cytokine cell signaling is that activation of these pathways by cytokines and their agonists is usually a very rapid and transient event (minutes) that results in somewhat longlasting consequences (modulation of cytokine gene expression). It is, thus, conceivable that a shortterm modulation of cell signaling pathways may have an impact on cytokine gene expression without having much negative consequences on other fundamental cellular processes. For this reason, it is important to understand the role of individual signaling pathways in inflammation and tissue destruction in periodontal disease. Because these pathways are common to several inflammatory mediators, including many cytokines, chemokines, cell-adhesion molecules, acute-phase proteins and anti-apoptotic proteins, their inhibition will probably prove more progress than current treatment strategies. This review aims at providing updated information on host-modulating therapies, focusing on control mechanisms to inhibiting the most important signal transduction pathways related to inflammatory periodontal disease.

\section{3- CELL SIGNALING PATHWAYS IN PERIODONTAL DISEASE}

As soon as bacterial biofilms accumulates in the teeth area adjacent to gingival margin, an inflammatory process is initiated, triggering a dynamic cascade of events. The main purpose of these events is the combat of microbial invaders through pro-inflammatory actions. These proinflammatory actions depend on the recognition of the external antigenic stimuli by host leukocytes of the innate immune response, e.g. macrophages, neutrophils, dendritic cells, natural killer cells and others. This recognition of external "danger" then triggers a signal that travels through the cytoplasm and reaches the nucleus, and ultimately the pattern of gene expression is altered by transcriptional and post-transcriptional mechanisms. The ability of the inflammatory response to clear the infection will determine the sequence of the process. Within 3-4 days the inflammatory process may be sufficiently robust to initiate connective destruction. If the initial innate immune response is not sufficient to resolve the aggression and eliminate the "danger" signals, then an adaptive immune response is initiated, involving lymphocytes that will produce immunoglobulins, cytokines and also try to clear out the aggression by direct cytotoxic mechanisms. Regardless of the type of host response (innate or acquired immunity), all cellular events depend on the activation of multiple signal transduction pathways, which may be affected by various factors both microbial- and host-derived, including lipopolysaccharide (LPS), proteases, cytokines and other enzymes ${ }^{47,80}$. Signal transduction depends on receptor-ligand interactions which usually involves some modification on the cytoplasmic proteins associated with these receptors. The most common modification associated with signal transduction is phosphorylation of specific aminoacid residues by kinases, which induces a conformational change on the tridimensional structure of the protein. Phosphorylation functions as a very efficient way to transfer energy and modulate their biological activity, since it does not involve de novo gene expression (i.e., the signaling intermediates are usually constitutively expressed by the cells and "ready to go into action", as soon as they are modified). Signal transduction pathways have a varying number of signaling intermediates that are activated (phosphorylated) sequentially and relay the energy to one or more protein substrates. These substrates can exert their biological effect as transcriptional factors, transcriptional repressors, by altering mRNA stability or translation efficiency. The complexity of the inflammatory network established during periodontal disease progression results from the activation of intracellular signaling pathways, which are determined by the nature of extracellular stimuli. In periodontal disease the most important pathways include the mitogen activated protein kinase (MAPK), nuclear factor kappa B (NF-kB) and janus tyrosine kinase-signal transducer and activator of transcription (JAK/STAT) ${ }^{3,20}$.

\section{1- MAPK pathway}

MAPKs are an evolutionarily conserved family of protein kinases that mediate fundamental biological processes and cellular responses to different extracellular stimuli through multiple receptors ${ }^{41}$. MAPKs are involved in signal transduction of extracellular hormones, growth factors, cytokines, bacterial antigens and environmental stresses and play a crucial role in many aspects of immune mediated inflammatory responses ${ }^{63,67}$. The three main sub-families of MAPKs are extracellular- 
regulated kinases (ERK-1/-2), c-Jun N-terminal activated kinases (JNK) and p38. ERK kinases are traditionally considered as being primarily activated by mitogens and growth factors while inducers of stress and pro-inflammatory cytokines are activated by JNKs and $p 38^{60}$, although this general concept does not apply to all cell types and to all external stimuli. However, there is evidence of crossactivation and interaction between various levels of the main MAPKs pathways (ERK and p38) ${ }^{64,86}$. The MAPK cascade consists of a series of threetired protein kinases, a MAPK and two upstream components, MAPK kinase (MAPKK) and MAPKK kinase (MAPKKK). Activation of the MAPKs results in phosphorylation of specific transcription factors that mediate gene transcription (Figure 1). The multiple interactions between the different MAPK cascades serve to integrate the responses and activate separate sets of genes ${ }^{43,63}$. All three MAPK families are expressed in periodontal disease ${ }^{20}$.

During initial interaction of pathogens with the host's immune system, pathogen-associated molecular patterns (PAMPs), such as LPS, peptidoglycans, lipoteichoic acid, or bacterial CpG-DNA can trigger cells of the innate immune system $^{52}$. Cytokines produced in response to this initial activation by PAMPs can also activate signal transduction pathways by autocrine or paracrine mechanisms. These microbial products and cytokines (e. g. IL-1 $\beta$ and TNF- $a$ ) act through the Toll receptors, IL-1 receptor (TIR) family or the TNF receptor family. Activation of these receptors triggers MAPK pathway (Figure 1), leading to activation of the transcription factor NF-KB, which is known to be relevant for cytokine gene expression ${ }^{43}$. The activation of MAPK/NF-KB pathway is a key to chronic inflammatory conditions such as rheumatoid arthritis ${ }^{81}$

p38 activation leads to increased expression of various cytokine genes by modulation of both transcriptional and post-transcriptional mechanisms. The contribution of each mechanism to the global change of gene expression varies with the cell type and nature of external stimulation, but among the genes that are at least partially modulated by post-transcriptional mechanisms involving modification of RNA-binding proteins as substrates of p38 MAPK are TNF-a, IL-8, IL$6, \mathrm{IL}-2$ and cyclooxygenase (COX)-233,61,91. Other genes are primarily regulated by transcriptional

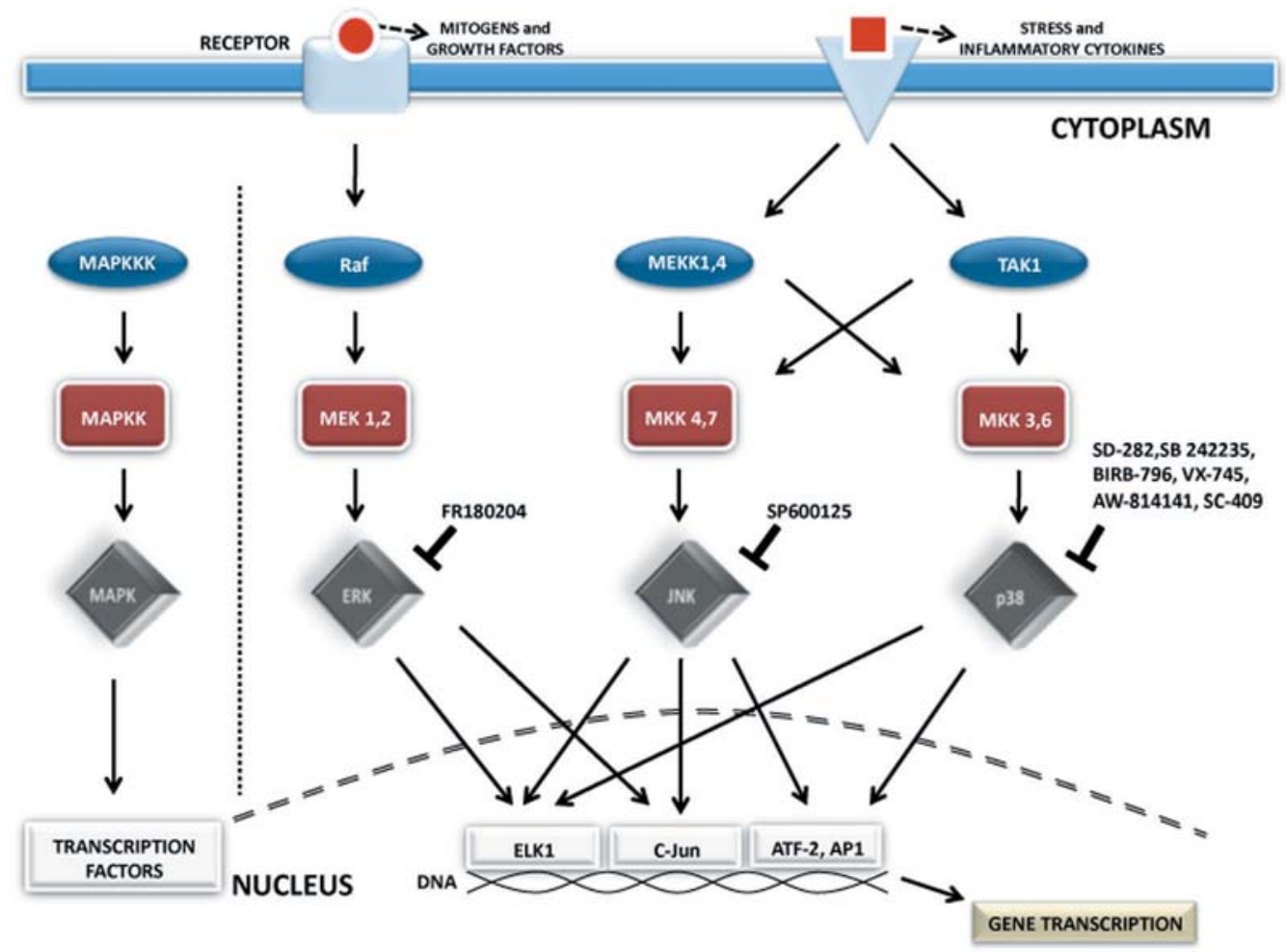

Figure 1- MAPK pathway: The three main sub-families of mitogen-activated protein kinases (MAPKs) are extracellularregulated kinases (ERK), c-Jun N-terminal activated kinases (JNK) and p38 that mediate immune cell functional responses to different extracellular stimuli through multiple receptors. The MAPK cascade consists of a series of three-tired protein kinases, a MAPK and two upstream components, MAPK kinase (MAPKK) and MAPKK kinase (MAPKKK). Activation of the MAPKs results in phosphorylation of a specific transcription factors that mediate gene transcription. Several biochemical compounds capable of inhibiting MAPKs are presented in the figure. Abbreviations: AP1, activating protein-1; ATF, activating transcription factor; ELK, Ets-like transcription factor associated kinase; MEK, MAPK/ERK Kinase; TAK, TGFb associated kinase 
mechanisms and include IL-1 $\beta, R A N K L$, chemokines and metalloproteinases ${ }^{7,70,72}$.

The evidence indicating a prominent role of MAPK pathways (in particular p38a MAPK) for cytokine gene expression and signaling, make them potential targets for anti-inflammatory therapeutics. Inhibitors targeting p38a MAPK pathway have been developed and preclinical and clinical data suggest that they exhibit anti-inflammatory activity ${ }^{36}$, as presented figure 4. Most of these protein kinase inhibitors interfere with phosphorylation or bind in the ATP binding site. Several compounds such as SD-282, SC-409, SB (SmithKline Beecham) -242235, AW-814141 and other capable of inhibit p38 have been studied in murine models of rheumatoid arthritis and/or periodontal disease and have prevented progression of the disease and bone resorption 4,12,49,51,69. The promising results obtained in both in vitro and in preclinical studies generated interest of pharmaceutical companies to develop protein kinase inhibitors. The p38 inhibitor BIRB796 (Boehringer Ingelheim Pharmaceuticals Inc., Ridgefield, CT, USA) and VX-702 have been tested in a phase II study in rheumatoid arthritis but shown limited results ${ }^{15,92}$. Studies to evaluate the safety and efficacy of other compounds in patients with arthritis are currently underway ${ }^{76}$. To date, efficacy of these compounds in arthritis appears limited and there are significant adverse reactions ${ }^{79}$. VX-745 was discontinued because in animal test revealed adverse neurological effects. Although no adverse effects were reported in human, gastrointestinal symptoms were described ${ }^{31,87}$.

Inhibitors of JNK and ERK have also shown efficacy in inhibiting the production of proinflammatory mediators ${ }^{32,89}$ (Figure 4). So far, no human trials have been initiated with these inhibitors. In murine model of rheumatoid arthritis, the JNK inhibitor SP600125 (Celgene Corporation, San Diego, California, USA), besides the reduction in the level of TNF-a, IFN-Y, IL-6, COX-2 and MMPs, also inhibit joint destruction in a rat adjuvant arthritis model ${ }^{32}$. Specific ERK inhibitors have been available but there is limited information about their potential therapeutic applications in inflammation ${ }^{83}$. Recently, a potent and selective inhibitor for ERK, FR180204, has been proven effective against mouse collagen-induced arthritis. This compound

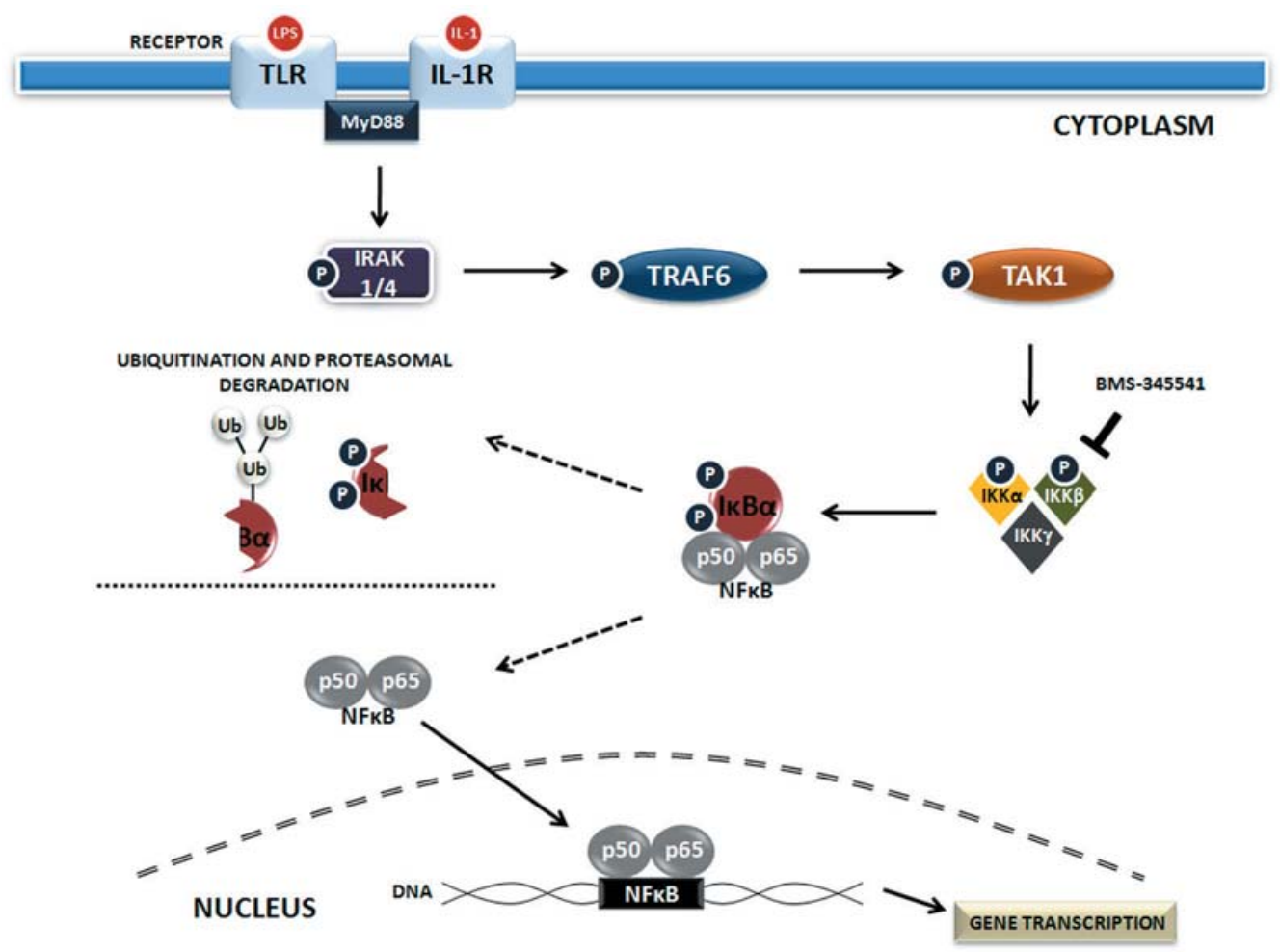

Figure 2- NF-KB pathway: IKBs bind to functional NF-kB transcription factors (p50/p60) in cytoplasm in absence of stimuli and prevent their nuclear translocation. Signaling through TNF receptor (TNFR), IL-1 receptor (IL-1R), or toll-like receptor (TLR) can activate a cascade that involves the recruitment of MYD88 (myeloid differentiation primary response gene 88) and IRAK (interleukin-1-receptor associated kinase). Activation of IRAK results in the phosphorylation of TNF-receptor associated factor 6 (TRAF6), leading to transforming growth factor- $\beta$-activated kinase 1 (TAK1) activation, which, in turn, is required for IKB kinase complex (IKK) phosphorylation. IKK then phosphorylates the IKBa protein, which results in ubiquitination, dissociation of $\mathrm{IKBa}$ from NF-KB and degradation of $\mathrm{IKBa}$ by the proteosome. The NF-KB protein then translocates to the nucleus where it binds to its specific DNA and initiates transcription of multiples genes. The IKK inhibitor, BMS-345541 prevents IKBa degradation and therefore activation of NF-KB 
suppresses the activation of $\mathrm{T}$ cells, which play a important role in progress of the disease ${ }^{56}$.

The MAPK inhibitors are capable of reducing the synthesis of pro-inflammatory cytokines. Many studies with these inhibitors have shown benefits in patients with inflammatory diseases such as rheumatoid arthritis and periodontal disease $27,37,59,62$. In several cases, however, the clinical studies have been stopped ${ }^{87}$. MAPKs play several physiological roles and suppression of these functions may lead to a number of problems. While many inhibitors have shown efficacy in clinical trials, side effects have prevented the development of some of these compounds. Therefore, most of these compounds have subsequently been discontinued. One of the underlying reasons for these unacceptable side effects might be the cross-reactivities against other kinases or other cellular signaling molecules ${ }^{14}$.

\section{2- NF-kB pathway}

NF- $\mathrm{BB}$ was first identified as a transcription factor that binds to a 10 base pairs (bp) DNA element in kappa immunoglobulin light-chain enhancer in B cells ${ }^{74}$. The NF-KB family of transcription factors has been shown to be involved in many different pathways and has a central role in regulating the expression of a wide variety of genes that control both innate and adaptive immune responses. Activated $\mathrm{NF}-\kappa \mathrm{B}$ has been detected in human synovial tissue on the early stage of joint inflammation ${ }^{26}$. Activation of the NF-KB pathway occurs in the presence of many pro-inflammatory mediators present in large quantities in tissues with periodontal disease such as bacterial LPS, TNF-a, IL-1, MMPs, COX2 and inducible nitric oxide synthase (iNOS) ${ }^{5,81}$. In vitro studies have established that both Porphyromonas gingivalis and other periodontal pathogenic bacteria can also activate NF-KB in periodontal tissues ${ }^{78}$. This activation of NF-KB in the presence of such a diversity of biologically active molecules is the consequence of the activation of other signaling pathways, including MAPKs and TLR pathways. A better understanding of the regulation of NF-KB pathways will provide a platform for developing specific therapeutics for inflammatory diseases. A recent study in patients with chronic periodontitis and healthy controls showed that activation of NF$\mathrm{KB}(\mathrm{p} 50 / \mathrm{p65})$ is significant in periodontally diseased tissues, suggesting the potential of NF-KB inhibitors in managing periodontitis ${ }^{3}$. In animal models of rheumatoid arthritis, the administration of NF-KB inhibitors seems to be effective ${ }^{53}$.

The NF- $\mathrm{KB}$ family consists of five members: REL-a (p65), NF-kB1 (p50; p105), NF-kB2 (p52; p100), c-REL and REL- $b^{24}$. These subunits, except REL- $b$, form homodimers and heterodimers to produce NF- $\mathrm{kB}$ transcription factors. The most common activating form in inflammatory reactions

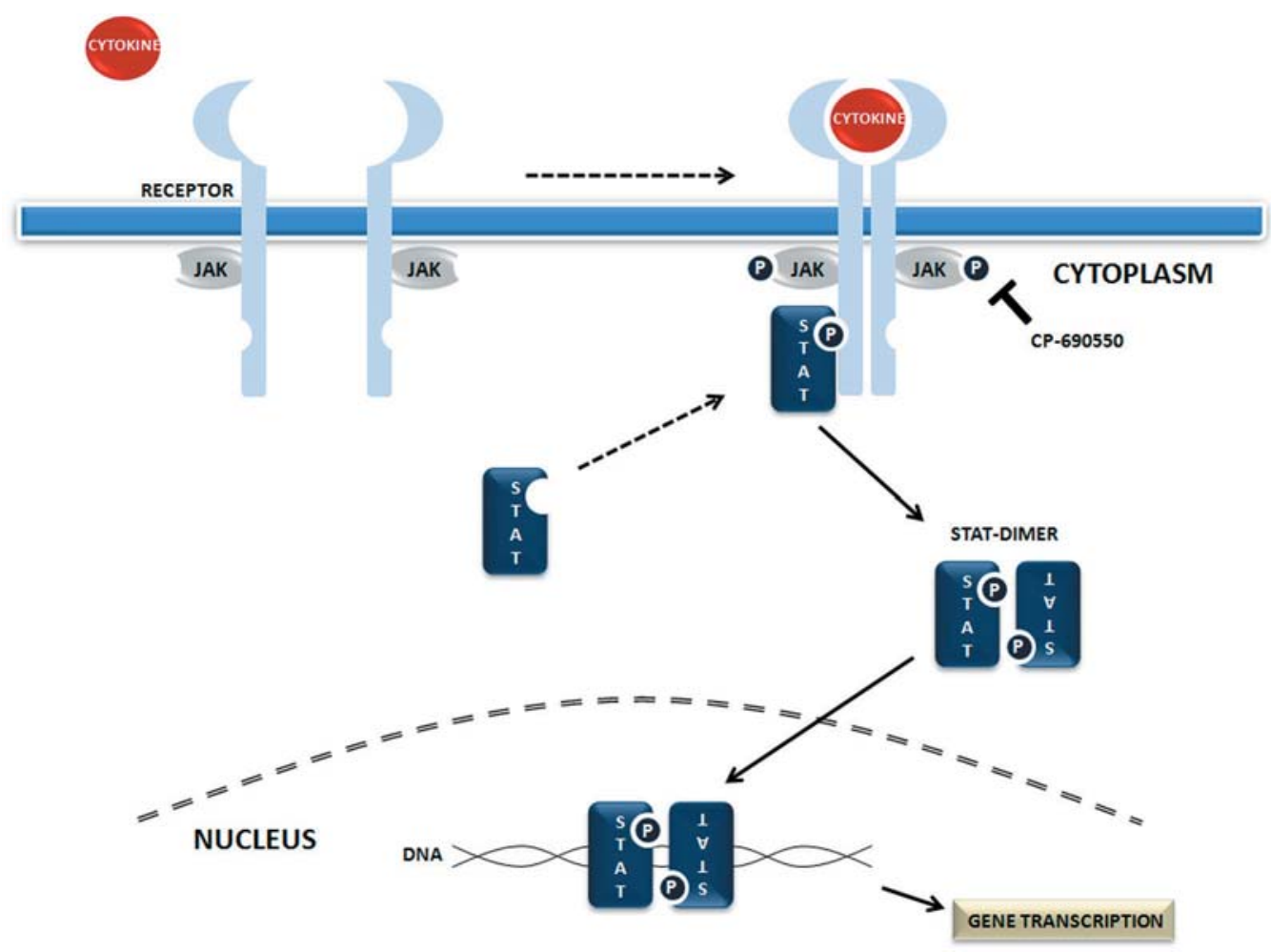

Figure 3- JAK/STAT pathway: the activation of Janus tyrosine kinases (JAK) after cytokine binds to its specific receptor at cell surface results in the phosphorylation of signal transducers and activators of transcription (STATs), which then dimerize and translocate to the nucleus where they can regulate gene transcription. The compound CP-690550 inhibits JAK3 and prevents activation of JAK/STAT pathway 
is a heterodimer of $p 50$ and p65. They bind to the NF-KB 5 ' $-3^{\prime}$ site and then activate or repress target gene transcription ${ }^{13,45}$. The key regulators of NF-KB are inhibitors of NF-KB (IKB), of which the most common are $I \kappa B a, I \kappa B \beta$ and $I \kappa B \varepsilon^{24}$. I $\mathrm{K} B s$ proteins bind to functional NF-kB dimers in cytoplasm in absence of stimuli and prevent their nuclear translocation. Signaling through IL-1 receptor (IL1R) or toll-like receptor (TLR) can activate a cascade that involves the recruitment of MYD88 (myeloid differentiation primary response gene 88 ) and IRAK (interleukin-1-receptor associated kinase). Activation of IRAK results in the phosphorylation of TNF-receptor associated factor 6 (TRAF6), leading to transforming growth factor- $\beta$-activated kinase 1 (TAK1) activation, which, in turn, is required for IKB kinase complex (IKK) phosphorylation. IKK then phosphorylates the IKBa protein, which results in ubiquitination, dissociation of IKBa from NF-KB and degradation of IKBa by the proteosome. The NF-KB protein then translocates to the nucleus where it binds to its specific DNA and initiates transcription of multiples genes, including cytokines, chemokines, matrix metalloproteinases and other inflammatory mediators (Figure 2). Many strategies to prevent activation of NF-KB are based on the modulation of IKB, as proteasome inhibitors that block degradation of IKB, and overexpression of IKB by recombinant protein or by gene therapy ${ }^{9}$. The IKK inhibitor, BMS (Bristol-Myers Squibb)-345541, was evaluated in the collagen-induced arthritis model in mice and decreased both synovial inflammation and joint destruction ${ }^{50}$ (Figure 4). Inhibition of the protein kinases that activate IKB may also prevent NF-KB activation. Other strategies to block NF-KB activity are being developed by pharmaceutical industries, and are based either on targeting the DNA-binding activity of NF-KB or blocking the nuclear translocation of NF-KB dimers.

Despite the potential use of this pathway in development of therapeutic interventions for immune/inflammatory diseases, NF-KB also participates in normal physiological process. Therefore, general blockade of NF- $\mathrm{kB}$ results in unwanted side effects as liver failure related to hepatocyte apoptosis ${ }^{48}$.

\section{3- JAK/STAT pathway}

Many cytokines and growth factors (interferons, interleukins, epidermal growth factor, growth hormone, erythropoietin and others) exert their biological functions through JAK-STAT signal transduction pathway ${ }^{55,73}$. Classically, interferons and interleukins, cytokines with key roles in regulating the immune response, activate enzymes called Janus kinases (JAK1, JAK2, JAK3 and Tyk2), which are associated with the cytoplasmic portion of the transmembrane receptors ${ }^{34}$. Activated JAKs, phosphorylate the cytoplasmic domain of the receptor leading the activation of its substrates, especially the proteins known as STATs (STAT1-4, $5 a, 5 b$, and 6). Upon phosphorylation, STATs may

\begin{tabular}{|c|c|c|}
\hline Compound & Target & Effects \\
\hline SD-282 & p38 & $\begin{array}{l}\text { LPS-induced periodontal disease, inflammatory cytokine expression, } \\
\text { osteoclastogenesis, and alveolar bone loss were reduced in rats model }{ }^{69} \\
\text { Cartilage and bone destruction in mice with collagen-induced arthritis were } \\
\text { reversed }^{51}\end{array}$ \\
\hline SC-409 & p38 & $\begin{array}{l}\text { Streptococcal cell wall-induced arthritis, joint swelling and bone destruction } \\
\text { were attenuated in rats }{ }^{49}\end{array}$ \\
\hline SB-242235 & p38 & Symptoms of adjuvant-induced arthritis in rats were significantly reduced ${ }^{4}$ \\
\hline AW-814141 & p38 & Inflammation in two different models of arthritis in mice were reduced ${ }^{12}$ \\
\hline BIRB-796 & p38 & Reduce join inflammation in a phase II study in rheumatoid arthritis ${ }^{92}$ \\
\hline VX-702 & p38 & $\begin{array}{l}\text { May not provide sustained suppression of the chronic inflammation seen in a } \\
\text { phase II study in rheumatoid arthritis }{ }^{15}\end{array}$ \\
\hline VX-745 & p38 & $\begin{array}{l}\text { Inhibits cartilage induced and adjuvant induced arthritis model }{ }^{31} \text { but was } \\
\text { discontinued because in animal test revealed adverse neurological effects }{ }^{87}\end{array}$ \\
\hline SP600125 & JNK & $\begin{array}{l}\text { Reduction in the level of TNF- } \alpha \text {, IFN- } \mathrm{y}, \mathrm{IL}-6, \mathrm{COX}-2 \text { and MMPs, also inhibits } \\
\text { joint destruction in a rat adjuvant arthritis model }{ }^{32}\end{array}$ \\
\hline FR180204 & ERK & Effective against mouse collagen-induced arthritis ${ }^{56}$ \\
\hline BMS-345541 & NF-kB & $\begin{array}{l}\text { Decreased both synovial inflammation and joint destruction in the collagen- } \\
\text { induced arthritis model in mice }{ }^{50}\end{array}$ \\
\hline CР-690550 & JAK3 & $\begin{array}{l}\text { Phase I and II clinical trials demonstrated the efficacy and safety of CP- } \\
690550 \text { in preventing transplant rejection and alleviating the symptoms of } \\
\text { rheumatoid arthritis and psoriasis }{ }^{88}\end{array}$ \\
\hline
\end{tabular}

Figure 4- Pharmacological compounds with potential host-modulation actions 
form homo- or hetero-dimers; which enables them to enter to the nucleus where they can regulate gene transcription ${ }^{55}$ (Figure 3 ). Although individual STAT proteins may be activated by multiple ligands, certain cytokines preferentially activate particular STATs. IFN-y preferentially activates STAT1 through JAK1/JAK2 and IL- 6 activates STAT3 through JAK1. This pathway is crucial to many responses like hematopoiesis, oncogenesis and immune/ inflammation regulation. However, abnormal activity of JAK/STAT pathway is associated with a wide variety of human malignancies such as cancer. Regulatory mechanisms controlling the duration of the signal include the downregulation of the receptor/ligand complex, degradation of signaling intermediates, inactivation of positive regulators by dephosphorylation (receptor, JAK or STAT) or activation of specific suppressors ${ }^{77}$.

The JAK-STAT pathway is the signaling target of many cytokines which are thought to have biologically significant roles in rheumatoid arthritis (IFN- $\gamma$, IL-2, IL-4, IL-6, IL-7, IL-10, IL-12, and IL-15) and in periodontal disease (INF- $\gamma$, TNF- $\alpha$, IL-1 IL-4, IL-6, and IL-10) ${ }^{8,66,85}$. Furthermore preliminary studies in human synovial tissue suggest that constitutive STAT activity is observed in rheumatoid arthritis ${ }^{35,39}$. Other recent study have shown that STAT3 and STAT5 activations were noted on the ligature-induced model of experimental periodontitis ${ }^{20}$. To date, no studies with STAT inhibitors are available in periodontal disease and in rheumatoid arthritis, despite the potential role of these proteins in expression of important genes related with inflammatory diseases.

Among the four JAKs, JAK3 and Tyk2 have been the focus of most interest in terms of drug development whereas experimental deficiency of JAK1 or JAK2 is lethal. Therefore, targeting these kinases would not be expected to be good targets $^{58,68}$. At moment, no Tyk2 inhibitor was developed. Tyk2 was involved in signaling by type I IFNs ${ }^{84}$. Targeting Tyk2 would be a useful strategy for the treatment of Th1 mediated disorders such as arthritis ${ }^{75}$. The JAK3 antagonist CP-690550 (Pfizer) showed potential benefits in treatment of rheumatoid arthritis ${ }^{88}$ (Figure 4).

It is now clear that JAK/STAT pathway have a fundamental role in inflammatory diseases onset and progression. This pathway can affect the expression of various genes with pro-inflammatory and anti-inflammatory activity. Furthermore, the modulation of this pathway on cytokine signaling increases the possibility that these proteins may prove to be excellent targets for the discovery of drugs that can manipulate cytokine outcomes to resolve disease.

\section{4- CONCLUSIONS}

Periodontal diseases are one of the most significant causes of tooth loss in adults and it is clear that both the pathogenesis and the clinical manifestations of this disease are, at least in part, due to abnormal immune and inflammatory responses. Wherefore, the importance of the host response in inflammatory process should be recognized by the fact it represents the opportunity to explore new treatment approaches. The adjunctive use of modulation of host response with traditional mechanical periodontal therapy has provided significant clinical benefits in the treatment of periodontal disease.

Improved knowledge of signal transduction mechanisms and gene regulation involved in immune responses, notably in pathways involving NF- $k B$, p38 MAP kinase and JAK/STAT, will certainly create new therapeutic targets useful in treating inflammatory disorders. Once these pathways are common to various inflammatory mediators, their blockade may be more effective than targeting specific cytokines. However these pathways are important in several other physiological processes and therefore their inhibition can also result in undesirable side effects.

The development of effective drugs targeting host response mechanisms may represent a new approach in adjunctive treatment of periodontal disease. Although these drugs offer great potential to modulate host response, a notable limitation of these agents is a lack of specificity and collateral effects. Drugs that inhibit destruction of the connective tissue in one periodontal site also interfere with wound healing at another, or worse, can predispose the patient to opportunist and/or acquired infections in other organ systems when these drugs are administered systemically. Thus, drugs that have beneficial effects for the treatment of periodontal disease may cause problems in other parts of body. Nevertheless, preliminary results indicate that the therapeutic potential of some of these drugs are promising for the management of rheumatoid arthritis and other inflammatory and chronic diseases. In the future, it is possible that host modulating drugs will provide new adjunctive therapeutic strategies for periodontal treatment.

\section{ACKNOWLEDGEMENTS}

Grant support was provided by grants \#2007/06332-4 and \#2007/06658-7 awarded by The State of São Paulo Research Foundation (FAPESP). 


\section{REFERENCES}

1- Albandar JM. Global risk factors and risk indicators for periodontal diseases. Periodontol 2000. 2002;29:177-206.

2- Alexander MB, Damoulis PD. The role of cytokines in the pathogenesis of periodontal disease. Curr Opin Periodontol. 1994:39-53.

3- Ambili R, Santhi WS, Janam P, Nandakumar K, Pillai MR. Expression of activated transcription factor nuclear factor-kappaB in periodontally diseased tissues. J Periodontol. 2005;76:1148-53. 4- Badger AM, Griswold DE, Kapadia R, Blake S, Swift BA, Hoffman SJ, et al. Disease-modifying activity of SB 242235, a selective inhibitor of p38 mitogen-activated protein kinase, in rat adjuvantinduced arthritis. Arthritis Rheum. 2000;43:175-83.

5- Baeuerle PA, Baichwal VR. NF-kappa B as a frequent target for immunosuppressive and anti-inflammatory molecules. Adv Immunol. 1997;65:111-37.

6- Baker PJ. The role of immune responses in bone loss during periodontal disease. Microbes Infect. 2000;2:1181-92.

7- Baldassare JJ, Bi Y, Bellone CJ. The role of p38 mitogenactivated protein kinase in IL-1 beta transcription. J Immunol. 1999;162:5367-73.

8- Berglundh T, Donati M. Aspects of adaptive host response in periodontitis. J Clin Periodontol. 2005;32:87-107.

9- Bondeson J, Foxwell B, Brennan F, Feldmann M. Defining therapeutic targets by using adenovirus: blocking NF-kappaB inhibits both inflammatory and destructive mechanisms in rheumatoid synovium but spares anti-inflammatory mediators. Proc Natl Acad Sci USA. 1999;96:5668-73.

10- Brown LJ, Löe H. Prevalence, extent, severity and progression of periodontal disease. Periodontol 2000. 1993;2:57-71.

11- Cho H, Lee KH, Colquhoun AN, Evans SA. Invasive oral aspergillosis in a patient with acute myeloid leukaemia. Aust Dent J. 2010;55:214-8.

12- Chopra P, Kulkarni O, Gupta S, Bajpai M, Kanoje V, Banerjee $M$, et al. Pharmacological profile of AW-814141, a novel, potent, selective and orally active inhibitor of p38 MAP kinase. Int Immunopharmacol. 2010;10:467-73.

13- Ciesielski CJ, Andreakos E, Foxwell BM, Feldmann M. TNFalpha-induced macrophage chemokine secretion is more dependent on NF-kappaB expression than lipopolysaccharidesinduced macrophage chemokine secretion. Eur J Immunol. 2002;32:2037-45.

14- Cohen P. Targeting protein kinases for the development of anti-inflammatory drugs. Curr Opin Cell Biol. 2009;21:317-24.

15- Damjanov N, Kauffman RS, Spencer-Green GT. Efficacy, pharmacodynamics, and safety of VX-702, a novel p38 MAPK inhibitor, in rheumatoid arthritis: results of two randomized, double-blind, placebo-controlled clinical studies. Arthritis Rheum. 2009;60:1232-41.

16- De Repentigny L, Lewandowski D, Aumont F, Hanna Z, Jolicoeur P. Oral mucosal cell response to Candida albicans in transgenic mice expressing HIV-1. Methods Mol Biol. 2009;470:359-68.

17- Dhasmana DJ, Dheda K, Ravn P, Wilkinson RJ, Meintjes G. Immune reconstitution inflammatory syndrome in HIV-infected patients receiving antiretroviral therapy: pathogenesis, clinical manifestations and management. Drugs. 2008;68:191-208.

18- Dinarello CA. Therapeutic strategies to reduce IL-1 activity in treating local and systemic inflammation. Curr Opin Pharmacol. 2004; 4:378-85

19- Gamonal J, Acevedo A, Bascones A, Jorge O, Silva A. Levels of interleukin-1 beta, -8 , and -10 and RANTES in gingival crevicular fluid and cell populations in adult periodontitis patients and the effect of periodontal treatment. J Periodontol. 2000;71:1535-45. 20- Garcia de Aquino S, Manzolli Leite FR, Stach-Machado DR, Francisco da Silva JA, Spolidorio LC, Rossa C Jr. Signaling pathways associated with the expression of inflammatory mediators activated during the course of two models of experimental periodontitis. Life Sci. 2009;84:745-54.
21- Garlet GP, Cardoso CR, Campanelli AP, Martins W Jr., Silva JS. Expression of suppressors of cytokine signaling in diseased periodontal tissues: a stop signal for disease progression? ] Periodontal Res. 2006;41:580-4.

22- Garlet GP, Martins W Jr, Fonseca BA, Ferreira BR, Silva JS. Matrix metalloproteinases, their physiological inhibitors and osteoclast factors are differentially regulated by the cytokine profile in human periodontal disease. J Clin Periodontol. 2004;31:671-9. 23- Gemmell E, Seymour GJ. Immunoregulatory control of Th1/ Th2 cytokine profiles in periodontal disease. Periodontol 2000. 2004;35:21-41.

24- Ghosh S, May MJ, Kopp EB. NF-kappa B and Rel proteins: evolutionarily conserved mediators of immune responses. Annu Rev Immunol. 1998;16:225-60.

25- Gilroy DW, Lawrence T, Perretti M, Rossi AG. Inflammatory resolution: new opportunities for drug discovery. Nat Rev Drug Discov. 2004;3:401-16.

26- Gilston V, Jones HW, Soo CC, Coumbe A, Blades S, Kaltschmidt $C$, et al. NF-kappa B activation in human knee-joint synovial tissue during the early stage of joint inflammation. Biochem Soc Trans. 1997;25:518S.

27- Goldstein DM, Gabriel T. Pathway to the clinic: inhibition of P38 MAP kinase. A review of ten chemotypes selected for development. Curr Top Med Chem. 2005;5:1017-29.

28- Golub LM, McNamara TF, Ryan ME, Kohut B, Blieden T, Payonk G, et al. Adjunctive treatment with subantimicrobial doses of doxycycline: effects on gingival fluid collagenase activity and attachment loss in adult periodontitis. J Clin Periodontol. 2001;28:146-56.

29- Graves D. Cytokines that promote periodontal tissue destruction. J Periodontol. 2008;79:1585-91.

30- Haddad JJ. Cytokines and related receptor-mediated signaling pathways. Biochem Biophys Res Commun. 2002;297:700-13.

31- Haddad JJ. VX-745. Vertex Pharmaceuticals. Curr Opin Investig Drugs. 2001;2:1070-6.

32- Han Z, Boyle DL, Chang L, Bennett B, Karin M, Yang L, et al. c-Jun $\mathrm{N}$-terminal kinase is required for metalloproteinase expression and joint destruction in inflammatory arthritis. J Clin Invest. 2001;108:73-81.

33- Hitti E, Iakovleva T, Brook M, Deppenmeier S, Gruber AD, Radzioch $D$, et al. Mitogen-activated protein kinase-activated protein kinase 2 regulates tumor necrosis factor mRNA stability and translation mainly by altering tristetraprolin expression, stability, and binding to adenine/uridine-rich element. Mol Cell Biol. 2006;26:2399-407.

34- Ihle JN, Kerr IM. Jaks and Stats in signaling by the cytokine receptor superfamily. Trends Genet. 1995;11:69-74.

35- Kasperkovitz PV, Verbeet NL, Smeets TJ, van Rietschoten JG, Kraan MC, van der Pouw Kraan TC, et al. Activation of the STAT1 pathway in rheumatoid arthritis. Ann Rheum Dis. 2004;63:233-9. 36- Kirkwood KL, Li F, Rogers JE, Otremba J, Coatney DD, Kreider JM, et al. A p38alpha selective mitogen-activated protein kinase inhibitor prevents periodontal bone loss. J Pharmacol Exp Ther. 2007;320:56-63.

37- Kirkwood KL, Rossa C Jr. The potential of p38 MAPK inhibitors to modulate periodontal infections. Curr Drug Metab. 2009;10:5567.

38- Kortylewski M, Yu H. Stat3 as a potential target for cancer immunotherapy. J Immunother. 2007;30:131-9.

39- Krause A, Scaletta N, Ji JD, Ivashkiv LB. Rheumatoid arthritis synoviocyte survival is dependent on Stat3. J Immunol. 2002; 169:6610-6.

40- Kuo LC, Poison AM, Kang T. Associations between periodontal diseases and systemic diseases: a review of the inter-relationships and interactions with diabetes, respiratory diseases, cardiovascular diseases and osteoporosis. Public Health. 2008;122:417-33.

41- Kyriakis JM, Avruch J. Mammalian mitogen-activated protein kinase signal transduction pathways activated by stress and inflammation. Physiol Rev. 2001;81:807-69. 
42- Lane N, Armitage GC, Loomer P, Hsieh S, Majumdar $\mathrm{S}$, Wang HY, et al. Bisphosphonate therapy improves the outcome of conventional periodontal treatment: results of a 12-month, randomized, placebo-controlled study. J Periodontol. 2005; 76:1113-22.

43- Lee JC, Laydon JT, McDonnell PC, Gallagher TF, Kumar S, Green $D$, et al. A protein kinase involved in the regulation of inflammatory cytokine biosynthesis. Nature. 1994;372:739-46.

44- Leitao RF, Ribeiro RA, Chaves HV, Rocha FA, Lima V, Brito GA Nitric oxide synthase inhibition prevents alveolar bone resorption in experimental periodontitis in rats. J Periodontol. 2005;76:956-63. 45- Li Q, Lu Q, Bottero V, Estepa G, Morrison L, Mercurio F, et al. Enhanced NF-kappaB activation and cellular function in macrophages lacking IkappaB kinase 1 (IKK1). Proc Natl Acad Sci USA. 2005;102:12425-30.

46- Liu D, Xu JK, Figliomeni L, Huang L, Pavlos NJ, Rogers $M$, et al. Expression of RANKL and OPG mRNA in periodontal disease: possible involvement in bone destruction. Int J Mol Med. 2003; 11:17-21.

47- Lu YC, Yeh WC, Ohashi PS. LPS/TLR4 signal transduction pathway. Cytokine. 2008;42:145-51.

48- Maeda S, Chang L, Li ZW, Luo JL, Leffert H, Karin M. IKKbeta is required for prevention of apoptosis mediated by cell-bound but not by circulating TNFalpha. Immunity. 2003;19:725-37.

49- Mbalaviele G, Anderson G, Jones A, De Ciechi P, Settle S, Mnich $S$, et al. Inhibition of p38 mitogen-activated protein kinase prevents inflammatory bone destruction. J Pharmacol Exp Ther. 2006;317:1044-53.

50- McIntyre KW, Shuster DJ, Gillooly KM, Dambach DM, Pattoli MA, Lu $P$, et al. A highly selective inhibitor of I kappa B kinase, BMS-345541, blocks both joint inflammation and destruction in collagen-induced arthritis in mice. Arthritis Rheum. 2003;48:26529.

51- Medicherla S, Ma JY, Mangadu R, Jiang Y, Zhao JJ, Almirez R, et al. A selective p38 alpha mitogen-activated protein kinase inhibitor reverses cartilage and bone destruction in mice with collageninduced arthritis. J Pharmacol Exp Ther. 2006;318:132-41.

52- Medzhitov R, Janeway CA Jr. Innate immunity: the virtues of a nonclonal system of recognition. Cell. 1997;91:295-8.

53- Miagkov AV, Kovalenko DV, Brown CE, Didsbury JR, Cogswell JP, Stimpson SA, et al. NF-kappaB activation provides the potential link between inflammation and hyperplasia in the arthritic joint. Proc Natl Acad Sci USA. 1998;95:13859-64.

54- Nishimoto N, Yoshizaki K, Miyasaka N, Yamamoto K, Kawai S, Takeuchi T, et al. Treatment of rheumatoid arthritis with humanized anti-interleukin- 6 receptor antibody: a multicenter, double-blind, placebo-controlled trial. Arthritis Rheum. 2004;50:1761-9.

55- O'Shea JJ, Gadina M, Schreiber RD. Cytokine signaling in 2002: new surprises in the Jak/Stat pathway. Cell. 2002;109:S121-31. 56- Ohori M. ERK inhibitors as a potential new therapy for rheumatoid arthritis. Drug News Perspect. 2008;21:245-50.

57- Page RC. The role of inflammatory mediators in the pathogenesis of periodontal disease. J Periodontal Res. $1991 ; 26: 230-42$.

58- Parganas E, Wang D, Stravopodis D, Topham DJ, Marine JC, Teglund $S$, et al. Jak2 is essential for signaling through a variety of cytokine receptors. Cell. 1998;93:385-95.

59- Pargellis C, Regan J. Inhibitors of p38 mitogen-activated protein kinase for the treatment of rheumatoid arthritis. Curr Opin Investig Drugs. 2003;4:566-71.

60- Patil C, Rossa C Jr, Kirkwood KL. Actinobacillus actinomycetemcomitans lipopolysaccharide induces interleukin- 6 expression through multiple mitogen-activated protein kinase pathways in periodontal ligament fibroblasts. Oral Microbiol Immunol. 2006;21:392-8.

61- Patil C, Zhu X, Rossa C Jr, Kim YJ, Kirkwood KL. p38 MAPK regulates IL-1beta induced IL- 6 expression through mRNA stability in osteoblasts. Immunol Invest. 2004;33:213-33.

62- Patil CS, Kirkwood KL. p38 MAPK signaling in oral-related diseases. J Dent Res. 2007;86:812-25.
63- Pearson G, Robinson F, Beers Gibson T, Xu BE, Karandikar $M$, Berman $K$, et al. Mitogen-activated protein (MAP) kinase pathways: regulation and physiological functions. Endocr Rev. 2001;22:153-83.

64- Perdiguero E, Ruiz-Bonilla V, Serrano AL, Muñoz-Cánoves P. Genetic deficiency of p38alpha reveals its critical role in myoblast cell cycle exit: the p38alpha-JNK connection. Cell Cycle. 2007;6:1298-303.

65- Reddy MS, Geurs NC, Gunsolley JC. Periodontal host modulation with antiproteinase, anti-inflammatory, and bone-sparing agents. A systematic review. Ann Periodontol. 2003;8:12-37.

66- Roberts FA, McCaffery KA, Michalek SM. Profile of cytokine mRNA expression in chronic adult periodontitis. J Dent Res. 1997;76:1833-9.

67- Robinson MJ, Cobb MH. Mitogen-activated protein kinase pathways. Curr Opin Cell Biol. 1997;9:180-6.

68- Rodig SJ, Meraz MA, White JM, Lampe PA, Riley JK, Arthur $C D$, et al. Disruption of the Jak1 gene demonstrates obligatory and nonredundant roles of the Jaks in cytokine-induced biologic responses. Cell. 1998;93:373-83.

69- Rogers JE, Li F, Coatney DD, Otremba J, Kriegl JM, Protter TA, et al. A p38 mitogen-activated protein kinase inhibitor arrests active alveolar bone loss in a rat periodontitis model. J Periodontol. 2007;78:1992-8.

70- Rossa C Jr, Liu M, Kirkwood KL. A dominant function of p38 mitogen-activated protein kinase signaling in receptor activator of nuclear factor-kappaB ligand expression and osteoclastogenesis induction by Aggregatibacter actinomycetemcomitans and Escherichia coli lipopolysaccharide. J Periodontal Res. 2008;43:20111.

71- Ryan ME. Clinical applications for host modulatory therapy. Compend Contin Educ Dent. 2002;23:1071-6,1079-80,1082.

72- Saklatvala J, Dean J, Clark A. Control of the expression of inflammatory response genes. Biochem Soc Symp. 2003:95-106. 73- Schindler CW. Series introduction. JAK-STAT signaling in human disease. J Clin Invest. 2002;109:1133-7.

74- Sen R, Baltimore D. Inducibility of kappa immunoglobulin enhancer-binding protein Nf-kappa B by a posttranslational mechanism. Cell. 1986;47:921-8.

75- Shaw MH, Boyartchuk V, Wong S, Karaghiosoff M, Ragimbeau J, Pellegrini $S$, et al. A natural mutation in the Tyk2 pseudokinase domain underlies altered susceptibility of B10.Q/J mice to infection and autoimmunity. Proc Natl Acad Sci USA. 2003;100:11594-9. 76- Smith RJ. Therapies for rheumatoid arthritis: hope springs eternal. Drug Discov Today. 2005;10:1598-606.

77- Starr R, Hilton DJ. Negative regulation of the JAK/STAT pathway. Bioessays. 1999;21:47-52.

78- Sugita N, Kimura A, Matsuki Y, Yamamoto T, Yoshie H, Hara K. Activation of transcription factors and IL- 8 expression in neutrophils stimulated with lipopolysaccharide from Porphyromonas gingivalis. Inflammation. 1998;22:253-67.

79- Sweeney SE, Firestein GS. Mitogen activated protein kinase inhibitors: where are we now and where are we going? Ann Rheum Dis. 2006;65:iii83-8.

80- Sweeney SE, Firestein GS. Primer: signal transduction in rheumatic disease - a clinician's guide. Nat Clin Pract Rheumatol. 2007;3:651-60.

81- Tak PP, Firestein GS. NF-kappaB: a key role in inflammatory diseases. J Clin Invest. 2001;107:7-11.

82- Tan AE. Periodontal maintenance. Aust Dent J. 2009;54:S1107.

83- Thalhamer T, McGrath MA, Harnett MM. MAPKs and their relevance to arthritis and inflammation. Rheumatology (Oxford). 2008;47:409-14.

84- Velazquez L, Fellous M, Stark GR, Pellegrini S. A protein tyrosine kinase in the interferon alpha/beta signaling pathway. Cell. 1992;70:313-22. 
85- Walker JG, Ahern MJ, Coleman M, Weedon H, Papangelis V, Beroukas D, et al. Expression of Jak3, STAT1, STAT4, and STAT6 in inflammatory arthritis: unique Jak3 and STAT4 expression in dendritic cells in seropositive rheumatoid arthritis. Ann Rheum Dis. 2006;65:149-56.

86- Wang Z, Yang H, Tachado SD, Capó-Aponte JE, Bildin VN, Koziel $\mathrm{H}$, et al. Phosphatase-mediated crosstalk control of ERK and p38 MAPK signaling in corneal epithelial cells. Invest Ophthalmol Vis Sci. 2006;47:5267-75.

87- Weisman $\mathrm{MH}$. What are the risks of biologic therapy in rheumatoid arthritis? An update on safety. J Rheumatol Suppl. 2002;65:33-8.

88- West K. CP-690550, a JAK3 inhibitor as an immunosuppressant for the treatment of rheumatoid arthritis, transplant rejection, psoriasis and other immune-mediated disorders. Curr Opin Investig Drugs. 2009;10:491-504.
89- Williams DH, Wilkinson SE, Purton $\mathrm{T}$, Lamont A, Flotow $\mathrm{H}$, Murray EJ. Ro 09-2210 exhibits potent anti-proliferative effects on activated T cells by selectively blocking MKK activity. Biochemistry. 1998;37:9579-85.

90- Williams RC, Beck JD, Offenbacher SN. The impact of new technologies to diagnose and treat periodontal disease. A look to the future. J Clin Periodontol. 1996;23:299-305.

91- Winzen R, Kracht M, Ritter B, Wilhelm A, Chen CY, Shyu AB, et al. The p38 MAP kinase pathway signals for cytokine-induced mRNA stabilization via MAP kinase-activated protein kinase 2 and an AU-rich region-targeted mechanism. EMBO J. 1999;18:496980.

92- Yong HY, Koh MS, Moon A. The p38 MAPK inhibitors for the treatment of inflammatory diseases and cancer. Expert Opin Investig Drugs. 2009;18:1893-905. 